Athens Journal of Business \& Economics -

Volume 8, Issue 1, January 2022 -Pages 9-20

\title{
Animal Welfare and Major Food Retailers
}

\author{
By Peter Jones ${ }^{*}$ and Daphne Comfort ${ }^{ \pm}$
}

\begin{abstract}
This paper offers an exploratory review of how some of the major US and European food retailers have publicly addressed animal welfare. The findings reveal that six interlinked themes, namely, strategic corporate commitment, animal welfare as good business policy, a focus on supply chains, policies on specific categories of animals and animal products, antibiotics, and auditing, illustrated the food retailers' approach to animal welfare. The authors raise a range of issues about the retailers' approach to animal welfare, including the aspirational nature of their commitments, the emphasis on regular audits, the role of external assurance in the reporting process, pressure from animal welfare campaigns, and the impact of the COVID-19 pandemic. The paper offers an accessible review how some of the major US and European food retailers have publicly addressed the issue of animal welfare.
\end{abstract}

Keywords: animal welfare, animal welfare statements, food retailers, supply chain, audit, external assurance

\section{Introduction}

The welfare of animals generates vociferous and passionate debate, and it has attracted increasing attention in the academic literature. Clark et al. (2016), for example, recognised that increases in productivity may have negative impacts on farm animal welfare in modern animal production systems, and provided a systematic review of public attitudes to animal welfare. Their review suggested that "the public are concerned about farm animal welfare in modern production systems" and that "naturalness and humane treatment were central to what was considered good welfare" (Clark et al. 2016). While consumer concerns about animal welfare are expressed in a variety of ways, but for many people their closest, though indirect, contact with animal welfare is through the food they buy, and then eat. That said, in some ways, animal welfare seems removed from the social practices of buying and eating animal products. Buller and Roe (2018), claimed "we largely take farm animals' lives (and deaths) for granted when we eat them and their products" and they suggested "for most of us, meat, egg and dairy consumption has become so distinct-geographically, morally aesthetically - from livestock that the animal disappears". More specifically, Buller (2016) claimed "shopping for welfare-friendly food products becomes an act of care-at-adistance". However, relatively little research has been published on the food retailers' approach to animal welfare. This exploratory paper looks to add to this work by reviewing, and reflecting on, how some of the major US and European

\footnotetext{
"Professor, School of Business and Technology, University of Gloucestershire, UK.

${ }^{ \pm}$Research Associate, School of Business and Technology, University of Gloucestershire, UK.
} 
food retailers have publicly addressed their approach to animal welfare. The paper includes an outline of the characteristics of animal welfare, a short literature review to provide an academic context and set of reference points for the paper, a review of the selected food retailers' approaches to animal welfare, some reflections on this approach, and some suggestions for future research.

\section{Animal Welfare}

Animal welfare is concerned with the general health and wellbeing of animals and spans a wide range of issues from the care of family pets, to the exploitation and abuse of animals. The welfare of animals can rouse deep passions and can generate fiercely contested debates, and while some voices stress the vulnerability of animals, for example, in intensive factory farms and medical research, others emphasise the need to increase food supplies and to develop new and better medicines. Essentially, the concept of animal welfare is concerned with how an animal is coping with the conditions in which it lives, and it is generally seen to include three elements, namely, an animal's normal biological functioning; its emotional state; and its ability to express (most) normal behaviours.

As such, the American Veterinary Medical Association (2020) suggested that an animal is seen to be in "a good state of welfare if (as indicated by scientific evidence) it is healthy, comfortable, well-nourished, safe, able to express innate behavior, and if it is not suffering from unpleasant states such as pain, fear, and distress". More popularly, commitments to animal welfare are often characterised by the "Five Freedoms", drawn up by the UK's Farm Animal Welfare Council (2009), namely freedom from hunger and thirst: freedom from discomfort; freedom from pain, injury or disease; freedom to express normal behaviour; and freedom from fear and distress.

Within Europe, the UK, where legislation on the treatment of cattle dates back to the 1820 's, can be seen as a pioneer in approaches to animal welfare, with legislation following in Germany, France, Switzerland and Sweden, later that century, while in the US, the first animal welfare laws can be traced back to the mid seventeenth century. More generally, Mench (2008) also argued that general awareness of animal welfare "occurred more slowly in the USA than in Europe" but it "is now gathering momentum as the agricultural industries and food retailers write guidelines and implement animal welfare audit programs in an attempt to reassure customers that farm animals are raised and slaughtered humanely".

\section{Literature Review}

Animal welfare within the food industry has attracted some attention in the literature. Well over two decades ago, Hughes (1995) identified a number of factors, including rising incomes, increasing education levels, consumer attachment to domestic, farmed and wild animals and birds, concerns about both animal 
welfare, and health and nutrition, which were shaping consumer concerns about animal welfare within the food industry at that time. Verbeke and Viane (2000) analysed consumer concerns about the ethical issues of meat safety and animal welfare from livestock production. Their analysis revealed that, meat safety emerged as an absolute, but minimum requirement, for the future success of livestock and meat production, and that animal welfare would become a critical issue, especially for consumer acceptance of pork and poultry.

Schroder and MacEachern (2004) explored ethical attitudes to meat purchases amongst both urban and rural consumers and reported that "individuals can hold two views on animal welfare. On the one hand, they may think as citizens influencing societal standards, and on the other, as consumers at the point of purchase. As citizens, they support the notion of animals being entitled to a good life; as meat consumers, they avoid the cognitive connection with the live animal". Much more recently Cornish et al. (2020) investigated consumers' preferences for higher welfare products with on-package animal welfare labels, and explored whether providing consumers with detailed information about the welfare conditions behind on-package animal welfare labels could have a positive influence on farm animal welfare. The authors concluded that "providing farm animal welfare information at the point-of-purchase could boost appreciation and demand for higher than conventional welfare products" (Cornish et al. 2020).

More generally, Buller et al. (2018) explored how animal welfare science and policy might articulate with global debates over food security and sustainability and they concluded that "the task of a broader animal welfare community is not to provide additional mechanisms for selective market performance but rather to help feed the multispecies world in a healthy and sustainable manner that matters to humans and animals alike". Ufer et al. (2019) explored "the economic foundations, challenges and opportunities for consumer acceptance of biotechnology applications in animal welfare" and argued that "if the benefits of biotechnological applications in agriculture are both welfare- and profitincreasing, producers may be able to capitalize on profitable biotechnologies while meeting consumer demands for improved welfare".

Limited research has been published on the leading food retailers' approaches to animal welfare. Lindgreen and Hingley (2003) examined the approach taken by Tesco to deal with consumers' concerns about animal welfare, and found that the retailer had worked with its suppliers to address such concerns, and suppliers were evaluated using a series of detailed key performance indicators. In classifying groups of themes in food retailers' corporate social responsibility reports and on own label products, Souza-Monteiro and Hooker (2017) suggested that health and safety and the environment were the most popular group, while animal welfare, along with community, biotechnology and novel foods were in the second rank of groups. Schulze et al. (2020), looked to explore how food retailers were motivated to take on the marketing of products with increased animal welfare standards, and their findings suggested that a focus on animal welfare can not only achieve more successful marketing, but can also help both consumers and farmers to change their consumption and production habits. 


\section{Frame of Reference and Method of Enquiry}

In looking to undertake an exploratory review of how the major US and European food retailers have publicly addressed animal welfare, the authors chose a simple method of enquiry, which they believe to be fit for purpose. Seven of the major US and European food retailers, namely, Walmart, Kroger, Albertsons, Lidl, Rewe, Tesco and Sainsbury's were selected for study. These retailers were selected because a preliminary survey revealed that that their approach to animal welfare was readily accessible on the Internet. Walmart is a US multinational retailer, and it trades from some 11,500 stores in 27 countries. Kroger's network of over 2,700 supermarkets and hypermarkets span states across the US. Albertson is a US grocery company and trades from over 2, 200 locations under several store brands including Albertsons, Carrs, Safeway, Shaws and United Supermarkets. Lidl is a German based international discount supermarket chain and trades from over 10,000 stores in Europe and the US. REWE is a large supermarket retailer with some 3, 300 stores in Germany, and the company also trades as the supermarket chain, BILLA, and the discount retailer, Penny, in several other European countries. Tesco is a multinational food retailer with some 3,400 stores in the UK and retail outlets in Ireland, Hungary, the Czech Republic, and Slovakia. Sainsbury's trades from over 600 supermarkets and some 800 convenience stores throughout the UK.

An Internet search was conducted using the name of each of the selected retailers and animal welfare as key phrases. The search was undertaken in October 2020 using Google as the search engine and it generated details of the current animal welfare statements, guidelines, and policies for all the selected retailers plus recent animal welfare reports for Lidl and Sainsbury's. These documents provided the empirical information for the paper. This material is in the public domain on the selected retailers' corporate websites and the authors took the considered view that they did not need to seek permission to use it. The paper looks to provide an exploratory review of how the selected major US and European food retailers publicly addressed animal welfare, rather than a systematic, comprehensive, or comparative analysis of animal welfare issues. The paper draws heavily on selected quotations drawn from the food retailers' corporate websites. The aim here is to explore how the retailers publicly expressed, and evidenced, their approaches to animal welfare, and the authors took the view that this was perhaps best captured in the retailers' own words, not least in that quotations could convey corporate authenticity, and offer greater depth of understanding (Corden and Sainsbury 2006). When outlining the issues of the reliability and the validity of the information drawn from Internet sources, Saunders et al. (2009) emphasised the importance of the authority and reputation of the source, and the citation of a specific contact that could be approached for additional information. In collecting the retailer's material on animal welfare, the authors felt that these two conditions were met. 


\section{Approaches to Animal Welfare}

There were variations in the ways the selected retailers' addressed animal welfare on their corporate websites, but rather than detailing each retailer's policy, the aim here is to draw out several themes that illustrate their general approach to animal welfare. More specifically, five/six interlinked themes were identified, namely, strategic corporate commitment, animal welfare as good business policy, a focus supply chains, policies on specific categories of animals and animal products, antibiotics, and auditing. Strategic commitment was expressed in a variety of ways. Tesco (2020), for example, claimed "animal welfare is important to us and to our customers. We are committed to working responsibly in this area, and to continue to progress and influence best practice in our supply chain". In a similar vein, Kroger (2019) emphasised "animal welfare is an important issue to Kroger, our customers and our associates. We have a long standing commitment to responsible business practices, including the humane treatment of animals". Rewe (2019) reported its commitment to "increasing animal welfare standards" and to "actively contribute to an improvement of livestock farming". Walmart (2020) stressed "we believe that farm animals in our supply chain should be treated humanely throughout their lives and that the welfare of farm animals should be considered in selection of all production systems, practices and technologies. Walmart U.S. and Sam's Club U.S. are committed to continuous improvement in the welfare of farm animals in our supply chain".

At the same time, some of the selected retailers also argued that their commitments to animal welfare were vitally important to their businesses. Sainsbury's (2019), for example, argued "treating animals well and keeping them healthy is not just the right thing to do, it also makes good business sense" and that "healthy well-managed animals are more likely to deliver better-tasting, higher quality products that our customers enjoy buying and consuming". In a similar vein, Lidl (2020) claimed "the welfare of farmed animals forms a key part of our continued dedication to our sustainability strategy", and "we believe this is in the interests of both our business, ensuring integrity and sustainability, and our customers who have told us that they are increasingly interested in buying produce that has been produced and sourced with strong welfare considerations".

The leading food retailers acknowledged the importance of their supply chains in addressing animal welfare. While Kroger (2019) explicitly recognised that the company "is not directly involved in raising or the processing of any animals" it claimed "we do, however, require our suppliers to adopt industryaccepted animal welfare standards that we endorse, and we monitor our suppliers for compliance with these standards". Walmart (2020) reported three elements in its animal welfare relationships with its suppliers. Firstly, "we expect that our suppliers will not tolerate animal abuse of any kind", secondly "we support the globally recognised Five Freedoms of animal welfare as an aspiration for animal welfare in our supply chain", and thirdly, "we will work with our supply chain partners to implement practices consistent with the Five Freedoms of animal welfare". 
In outlining its approach to "working in partnership with farmers and suppliers" Sainsbury's (2019) stressed its commitment to "working with our farmers to continuously improve the lives their animals lead" and that all its farmers have to meet "exacting animal health and welfare standards". Lidl (2020) claimed that its animal welfare standards "are continually evolving and go beyond legal requirements through all stages of the supply chain", while Tesco (2020) claimed "we work collaboratively with our suppliers, grower, farmers and fishermen... to identify ways in which high standards of animal welfare can be assured in a manner which is achievable for our supply base".

Some of the selected food retailers reported policies for specific categories of animals and animal products. Sainsbury's (2019) claimed "we adapt our animal health and welfare approach to meet each species particular needs". In outlining its policy on lamb, for example, Sainsbury's (2019) reported "we make sure that our lambs are reared as naturally as possible", that "they stay with their mothers, suckle freely, and live in family groups until they are weaned" and that "after that lambs stay together as a group but their diet is based entirely on grass and forage". In a similar vein, Rewe (2019) reported pursuing "various approaches to minimise problem areas for different types of farm animals" and that the company "continuously tries to develop and support alternatives for important hotspots or problems with regard to animal welfare for the respective livestock species". More specifically, Rewe (2019) reported its policies on poultry, pigs, rabbits, and meat production. Kroger (2019) recognised that "sows in the pork industry may experience negative and behavioural health impacts when housed in gestation stalls during pregnancy", that "group housing is a viable alternative", and that the company has asked its "suppliers to transition away from gestation stalls to group housing or free range environments". Lidl (2020) emphasised that its certification scheme for turkey suppliers ensured that "birds have continual access to food, water and have the ability to roam at will inside the barns in which they are raised".

Antibiotic resistance is a major public health issue and the increased use of antibiotics in both human and veterinary medicine has enhanced naturally occurring resistance. Walmart (2020), for example, recognised that "antibiotics are one of many critical tools used to keep animals healthy and that they should be used responsibly to preserve the effectiveness of antibiotics in human and veterinary medicine" and asserted its belief that "antibiotics should only be used for medical purposes (treatment, control and prevention of disease) and not for growth promotion". Further, Walmart (2020) reported that it looked to its suppliers to "promote transparency by providing an antibiotics management report to Walmart and publicly reporting antibiotic use on an annual basis". Lidl (2020) argued "the use of antibiotics should not be a replacement for good animal husbandry", that "we encourage our suppliers to optimise welfare, health, hygiene and the biosecurity of animals in order to reduce the need for antibiotic treatments", and that suppliers were to use antibiotics "as little as possible and as much as necessary, while keeping animal welfare as the primary focus". More generally, many large food retailers also had a range of animal welfare policies, 
covering cloning and growth promoters, confinement, permitted mutilations, stunning and slaughter, research, development and training, and transport.

A commitment to auditing was also a common feature in the selected food retailers' approach to animal welfare. Kroger (2019), for example, reported requiring "all beef, pork, chicken, turkey and egg suppliers to provide evidence of annual animal welfare audit to Kroger, as part of doing business with us". These audits "are to align with our accepted animal welfare standards and are to be conducted by reputable independent commercial third party auditing companies". Walmart's (2020) animal welfare policy stipulates that each fresh pork supplier "must have on-farm video monitoring for sow farms and will be subject to unannounced animal welfare video audits by an accredited and independent thirdparty" and suppliers "must implement an internal annual animal welfare audit for all farms that includes a grading system and corrective action tracking". Under the banner, "making sure our standards are met", Sainsbury's (2019) claimed "we implement our farm animal and welfare policies by working with independent auditors, suppliers and processors, and directly with our farmers". Further, Sainsbury's (2019) reported monitoring compliance with its various animal welfare policies "both through factory audits, carried out by our internal teams, and via on-farm audits undertaken by our agricultural consultants and third party assessors". Lidl (2020) emphasised that all its food producers are required to complete annual audits that cover a multitude of standards including animal welfare credentials, while Albertsons (undated) reported that "we conduct annual humane handling audits through our internal professional animal certification organization".

\section{Reflections}

In publicly outlining their approaches to animal welfare, the selected US and European food retailers have emphasised their commitment to animal welfare and described the ways that have looked to fulfil such commitments, but several issues merit reflection and discussion. While the selected companies were often at their most emphatic in emphasising their commitment to animal welfare, some of the claimed commitments are explicitly aspirational and expectational. Such corporate aspirations and expectations can certainly be seen to reflect public concerns about animal welfare but given that the selected food retailers have global reach and source animal products across extensive geographical areas, which may have different views on animal welfare, fulfilling their animal welfare commitments presents complex challenges.

These challenges are all the greater because the food retailers' commitments to animal welfare are at least one step removed from their own operations, which effectively reduces their direct control over welfare measures. Here, a major element in the selected food retailers' approach to animal welfare is the regular independent audits of their suppliers. However, in examining consumer concerns about food safety, the environment and animal welfare, Haggarty (2009) argued that audit-based governance is effectively shaped by the food industry itself, and 
that "grocery marketers translate consumer preferences into checklists of acceptable farming practices in negotiation with farming sector lobbies, consumer groups and other participants in agri-food systems". More specifically, in reviewing the role of "audit in animal welfare", Escobar and Demeritt (2016) highlighted the general "tendency for audit processes to become decoupled from the qualities they are meant to assure". As such, there is the danger that the audit exercises which the leading food retailers claim as a major feature of their corporate commitment to animal welfare, become a routine reporting end in themselves, rather than a means to an end.

More generally, major food retailers may well look to use their annual corporate social responsibility and sustainability reports to outline their commitments to animal welfare and to evidence their achievements in meeting such commitments. Whether food retailers will look to include detailed key performance indicators, as suggested by Lindgreen and Hingley (2003) almost two decades ago, in their reporting processes remains to be seen. At the same time, if major food retailers are to build confidence and stakeholders trust in their delivery of animal welfare commitments, and to avoid accusations of greenwashing, this effectively demands independent external assurance of the corporate social responsibility and sustainability reporting process. However, work on the assurance of food retailers' corporate social responsibility and sustainability reports undertaken by Jones et al. (2014) revealed "considerable variation in the nature and the scope of the assurance processes undertaken, at best the accent is on limited assurance and some concerns are expressed about the independence of the assessment process". While commissioning comprehensive independent external assurance, within large, complex and geographically widespread supply chains can be a costly and time consuming process, it is one which major food retailers will need to address more wholeheartedly, if they are to establish the integrity, reliability, and credibility of their commitments to animal welfare.

The food retailers, and more generally the food industry, face strident public and pressure group criticism about animal welfare. Tescopoly (undated), for example, an alliance launched in 2006 to highlight and challenge the negative impacts of Tesco's behaviour along its supply chain, argued that "supermarkets have enormous influence over the animal welfare standards used to produce the meat, milk and eggs that they sell". Further Tescopoly (undated) argued that 'as a result of supermarket buying power, which drives down prices paid to suppliers, farmers are expected to work to impossibly small margins", and that "in many cases they have no option but to intensify production in order to try to cover their costs". Tescopoly (undated) concluded that "the capture and control of the whole food supply chain by the supermarkets is a major contributor to poor animal welfare". Walmart has also faced pressure from a number of Non-Governmental Organisations, including, The Humane League and Mercy for Animals for its failure to implement measures to improve animal welfare.

At the time of writing, it is impossible to consider the major US and European food retailers' approaches to animal welfare issues without some reference to COVID-19, not least because the pandemic has disrupted global supply chains and changed consumer habits and behaviours. On the one hand, trade reports that 
many abattoirs and meat packing and processing plants were COVID-19 hotspots and were closed, albeit temporarily, and restrictions on international trade have disrupted many traditional supply chains. On the other hand, public fears and concerns about the COVID-19 pandemic, about the claimed tracing of its origins to a wholesale food market in China, and about the reported incidences of high levels of the virus amongst people working in food processing and packing plants in a number of countries, have heightened consumer awareness about the safety of animal products within food supply chains.

Given the wide ranging impact of COVID-19, it remains to be seen if, the leading food retailers will continue to commit the financial resources required to address continuing animal welfare concerns, or if they will concentrate on looking to restructure their business models to better respond to new consumer demands in a changing business environment. Looking to alternative futures, Plant Based News (2020), a media outlet producing content about veganism and plant based living, suggested that "with growing concerns about food safety in light of the COVID-19 pandemic and estimates that three out of every four new or emerging infectious diseases in people come from animals, it's about time that food companies ramped up their efforts to prevent the spread of such diseases". Further Plant Based News (2020) claimed that "the immune systems of animals raised on lower welfare factory farms are far weaker than any other; couple this with the immense overcrowding seen on these intensive farms - where some 90 percent of farmed animals are raised - and the risk of contracting and spreading dangerous diseases is worryingly high".

\section{Conclusion}

This paper has outlined the ways in which a number of major US and European food retailers have publicly addressed their approaches to animal welfare. Six interlinked themes illustrate the retailers' approach to animal welfare namely, strategic corporate commitment, animal welfare as good business strategy, a focus on supply chains, policies on specific categories of animals and animal products, antibiotics, and auditing. However, some of the food retailer's future commitments to continuing improvements in animal welfare were aspirational, and at least one step removed from production. At the same time, there are concerns about auditing and the external assurance of their achievements in meeting animal welfare commitments, and about the welfare of animals in the retailers' supply chains. While published research on food retailers' approaches to animal welfare has, to date, been limited, some of the findings of the current exploratory paper are relevant to that research. The findings support Verbeke and Viane's (2000) belief that animal welfare would become an increasingly critical issue for consumers. At the same time the selected food retailers' recognition that commitments to animal welfare makes good busines sense, can be seen to be consistent with Schulze et al.'s (2020) finding that a focus on animal welfare can help to achieve more successful marketing. 
The paper has its limitations, not least in that it is based on a small number of major US and European food retailers, that it draws its material exclusively from Internet sources and that does not include any empirical material collected from face to face interviews or focus group sessions with the selected food retailers, or their suppliers. However, the authors believe that as an exploratory paper it provides a platform for future research in what seems likely to become an important area for scholars interested in food retailers' approach to animal welfare. At the corporate level, for example, research may help to increase understanding not only of why, and how major food retailers develop their policies on animal welfare and how they look to elicit stakeholders' opinions, but also of how they take account of wider pressure group campaigns in formulating such policies. Research into how animal welfare concerns inform the relationships between the leading food retailers and their suppliers, and on the locus of power within such relationships, also merits attention. At the same time, research on if, and how, more explicit, and verifiable, animal welfare policies affect profit margins, stock market performance and reputation, will inform understanding of the workings of potentially new business models within food retailing.

At the operational and consumer level, many research questions arise, including, how the leading retailers have incorporated animal welfare policies into both general marketing messages as well as into marketing messages at the point of sale; if greater consumer awareness of a company's approach to animal welfare influences buying behavior and retailer patronage; and although the current paper has explored large retailers' approaches to animal welfare, an examination of small and medium sized retailers' policies on animal welfare, would broaden the scope of this genre of work. More generally, a focus on exploring alternative ways of organising food retailing, possibly more communally at a local level, for example, and making it more accountable to animal welfare considerations, might be seen to provide valuable insights into the future of food retailing.

\section{References}

Albertsons (undated) Our values: products. Retrieved from: https://www.albertsonsco mpanies.com/our-values/products.html. [Accessed 10 October 2020]

American Veterinary Medical Association (2010) Animal welfare! What is it? Retrieved from: https://www.avma.org/resources/animal-health-welfare/animal-welfare-whatit. [Accessed 24 July 2020]

Buller H (2016) Animal geographies III; ethics. Progress in Human Geography 40(3): $422-430$.

Buller H, Roe E (2018) Food and animal welfare. London: Bloomsbury Academic.

Buller H, Blockhuis H, Jensen P, Keeling L (2018) Towards animal welfare and sustainability. Animals 8(6): 81 .

Clark B, Stewart GB, Panzone LA, Kyriazakis I, Frewer LJ (2016) A systematic review of public attitudes, perceptions and behaviours towards production diseases associated with farm animals. Journal of Agricultural and Environmental Ethics 29(3): 455478 . 
Corden A, Sainsbury R (2006) Using verbatim quotations in reporting qualitative social research: researchers' views. Retrieved from: https://www.york.ac.uk/inst/sp $\mathrm{ru} / \mathrm{pubs} / \mathrm{pdf} / \mathrm{verbquotresearch.pdf.} \mathrm{[Accessed} 8$ July 2020]

Cornish AR, Briley D, Wilson BJ, Raubenheimer D, Schlosberg D, McGreevy PD (2020) The price of good welfare: does informing customers about what on-package labels mean for animal welfare influence their purchase decisions. Appetite 148(May): 104577.

Escobar MP, Demeritt D (2017) Paperwork and the decoupling of audit and animal welfare: The challenges of materiality for better regulation. Environment and Planning C: Politics and Space 35(1): 169-190.

Farm Animal Welfare Council (2009) Farm animal welfare in Great Britain; past present and future. Retrieved from: https://assets.publishing.service.gov.uk/government/uplo ads/system/uploads/attachment_data/file/319292/Farm_Animal_Welfare_in_Great_ Britain_-_Past_Present_and_Future.pdf. [Accessed 9 September 2020]

Haggarty J, Campbell H, Morris C (2009) Keeping the stress off the sheep? Agricultural intensification, neoliberalism and good farming in New Zealand. Geoforum 40(5): $767-777$

Hughes D (1995) Animal welfare: the consumer and the food industry. British Food Journal 97(10): 3-7.

Jones P, Comfort D, Hillier D (2007) Marketing and corporate social responsibility within food stores. British Food Journal 109(8): 582-593.

Jones P, Hillier D, Comfort D (2014) Assurance of the leading UK food retailers' corporate social responsibility/sustainability reports. Corporate Governance 14(1): 130-138.

Kroger (2019) Animal welfare policy. Retrieved from: https://www.thekrogerco.com/wpcontent/uploads/2018/07/The-Kroger-Co_AnimalWelfarePolicy_2018-July.pdf. [Accessed 11 October 2020]

Lidl (2020) Farm animal health and welfare policy. Retrieved from: file:///C:/Users/As ua/Downloads/Farm\%20Animal\%20Health\%20and\%20Welfare\%20Policy\%20202 0\%20(3).pdf. [Accessed 23 September 2020]

Lindgreen A, Hingley M (2003) The impact of food safety and animal welfare on supply chain management; the case of the Tesco meat supply chain. British Food Journal 105(6): 328-349.

Mench JA (2008) Farm animal welfare in the USA; farming practices, research, education, regulation, and assurance programs. Applied Animal Behaviour Science 113(4): 298312.

Plant Based News (2020) Is COVID-19 the Beginning of the end for McDonalds. Retrieved from: https://www.plantbasednews.org/opinion/beginning-of-end-for-mcdonalds. [Accessed 19 September 2020]

Rewe (2019) Guidelines for animal welfare. Retrieved from: https://www.rewe-group. com/dam/de/nachhaltigkeit/leitlinien-downloads/leitlinien/guideline-animal-welfare. [Accessed 11 October 2020]

Sainsbury's (2019) Animal health and welfare policy. Retrieved from: https://www.about. sainsburys.co.uk/ /media/Files/S/Sainsburys/CRS\%20Policies\%20and\%20Reports/ AnimalHealthWelfareReport2019.pdf. [Accessed 22 September 2020]

Saunders M, Lewis P, Thornhill A (2009) Research methods for business students. UK: Prentice Hall, Harlow.

Schroder MJA, MacEachern MGC (2004) Consumer value conflicts surrounding ethical meat purchase decisions: a focus on animal welfare. International Journal of Consumer Studies 28(2): 168-177. 
Schulze M, Spiller A, Risius A (2020) Food retailers as mediating gatekeepers between farmers and consumers in the supply chain of animal welfare meat - Studying retailers' motives in marketing pasture-fed beef. Food Ethics 3(3): 42-52.

Souza-Monteiro D, Hooker N (2017) Comparing UK food retailers' corporate social responsibility strategies. British Food Journal 119 (3): 658-675.

Tesco (2020) More information on our UK animal welfare. Retrieved from: https://www. tescoplc.com/sustainability/publications/policies/downloads/animal-welfare-policygroup/more-information-on-our-uk-animal-welfare/. [Accessed 10 October 2020]

Tescopoly (undated) Animal welfare. Retrieved from: http://www.tescopoly.org/animalwelfare. [Accessed 22 September 2020]

Ufer D, Ortega DL, Wolf CA (2019) Economic foundations for the use of biotechnology to improve animal welfare. Trends in Food and Science Technology 91(Sep): 129-138.

Verbeke WAJ, Viane J (2000) Ethical challenges for livestock production: meeting consumer concerns about meat safety and animal welfare. Journal of Agricultural and Environmental and Ethics 1(12): 141-151.

Walmart (2020) Animal welfare position. Retrieved from: https://corporate.walmart.com/ policies\#animal-welfare-position. [Accessed 11 October 2020] 